\section{Higiene como prática individual e como instrumento de Estado}

\author{
Hygiene as individual \\ practice and as an \\ instrument of the State
}

\author{
Rafael Mantovani ${ }^{i}$ \\ ' Doutor em Sociologia, Programa de Pós-graduação \\ em Sociologia/Universidade de São Paulo. \\ São Paulo - SP - Brasil \\ orcid.org/0000-0002-4940-8328 \\ rafamantovani@gmail.com

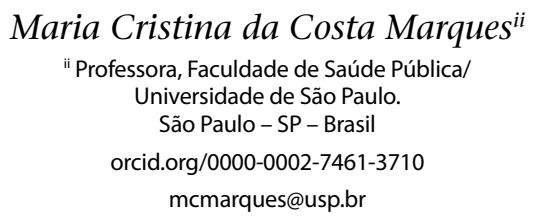

Recebido em 28 fev. 2018.

Aprovado em 4 jun. 2018.
MANTOVANI, Rafael; MARQUES, Maria Cristina da Costa. Higiene como prática individual e como instrumento de Estado. História, Ciências, Saúde Manguinhos, Rio de Janeiro, v.27, n.2, abr.-jun. 2020, p.337-354.

\section{Resumo}

O estudo esboça algumas compreensões sobre a palavra "higiene". A partir do Renascimento, a ideia advinda da Grécia Antiga voltou a ser trabalhada, primeiramente como método para uma organização dietética e moral da vida que visava ao seu prolongamento. De uma espécie de cuidado de si, transformouse em conceito de governança, cujo objetivo era o prolongamento da vida dos súditos/cidadãos. O debate teórico sobre o que era higiene pública mostra sua faceta eminentemente política: não apenas era um ramo da economia política, mas também eram analisadas as propostas dos higienistas de acordo com seu maior ou menor impacto na política. A batalha político-científica resultou na vitória de certas compreensões de ação estatal, e no esquecimento e na negligência de outras.

Palavras-chave: higiene; higiene pública; longevidade; economia política; biopoder.

\section{Abstract}

This study outlines some understandings of the word "hygiene." The notion that originated in ancient Greece first began to be adopted as a system of diet and morals to prolong the lifespan. From a type of self-care, this idea transformed into a concept of governance to extend the lives of subject-citizens. The theoretical debate about what public hygiene used to be shows its eminently political side: not only was hygiene a branch of the political economy, the ideas of hygienists were also analyzed as to the degree of impact they had on policy. After political and scientific battles, certain understandings of government action emerged victorious, while others were forgotten and neglected.

Keywords: hygiene; public hygiene; longevity; political economy; biopower. 
P ara o senso comum atual, higiene é sinônimo de limpeza. Nem sempre foi assim, e os especialistas em saúde bem o sabem. Atualmente, as palavras higienismo e higienista são, diversas vezes, usadas de maneira pejorativa, pois higiene ganhou o sentido de uma intervenção autoritária, centralizadora e de controle social por parte do Estado sobre os indivíduos. ${ }^{1}$ A "criminalização" ocorre por se associar higiene a esse tipo de "medicalização da vida" ou à eugenia (Guimarães, 2013, p.182). A higiene pode, de fato, estar próxima daquilo de que tem sido acusada, mas nem sempre foi assim. Hygeinos, em grego, significava "saudável" (Vigarello, 1988, p.168), e Hygeia era a deusa grega da saúde. Os conceitos de higiene e de saúde, desde os gregos, estão muito próximos, e, conforme se verá, estiveram durante muito tempo associados às ideias de dieta alimentar e sobriedade. O primeiro higienista da Idade Moderna, Luigi Cornaro (1467-1565), não associava higiene a limpeza.

O conceito de higiene variou de acordo com o meio social e político. Essa variação é um dos objetos deste artigo: compreender as mudanças da concepção do período que vai do Renascimento até o final do século XIX. Para isso, pretende-se focalizar três questões: (1) analisar o que os higienistas defendiam para se ter uma vida saudável, considerando os autores que se autointitulavam dessa maneira ou eram assim caracterizados pelo meio literário e/ou científico; (2) apresentar a maneira como a higiene pessoal, transformada em higiene social, tornou-se política de Estado a partir do século XVIII; (3) expor os embates entre as concepções de higiene social cujas demandas poderiam resultar em grandes modificações econômicas e aquelas que manteriam a estrutura econômica hierárquica.

Trata-se, portanto, de um ensaio teórico que se concentra na palavra higiene e nas suas mudanças conceituais no decorrer do tempo, o que nos indica algo sobre as sociedades em questão. Para a seleção das fontes, foram utilizados os textos clássicos considerados seminais, ou de referência, por Gruman (1966), Rosen $(1963,1993)$ e Foucault $(1979$, 2008a). Os teóricos da higiene e da higiene pública serão apresentados no decorrer do texto, quando aparecerem as conexões (ou a ausência de conexões) dos seus pensamentos sobre a mesma palavra.

Ao comparar as mudanças da palavra higiene no tempo e no espaço, podemos ter alguma compreensão de determinadas forças sociais, políticas, econômicas e acadêmicas em disputa. Não poderíamos, dessa maneira, ignorar as inter-relações entre as esferas de poder - político, econômico e acadêmico - na conformação recíproca do que se esperava e do que podia ser repreensível no processo de legitimação dos grupos internos e, também, na busca de reconhecimento por parte dos aspirantes aos quadros de mando de cada campo (chamados por Bourdieu de profanos):

A fronteira entre o que é politicamente dizível ou indizível, pensável ou impensável para uma classe de profanos determina-se na relação entre os interesses que exprimem esta classe e a capacidade de expressão desses interesses que a sua posição nas relações de produção cultural e, por este modo, política, lhe assegura. ... a passagem do implícito ao explícito, da impressão subjetiva à expressão objetiva, à manifestação pública num discurso ou num ato público constitui por si um ato de 'instituição' e representa por isso uma forma de oficialização, de legitimação (Bourdieu, 2007, p.165-166; destaque no original). 
E essa busca por legitimação impõe a concorrência interna para que sejam satisfeitos os interesses dos mandantes, na homologia entre as esferas sociais (seja a artística, a religiosa, a acadêmica) e a política.

Compreende-se que os grandes cientistas do passado não foram aqueles que descobriram verdades, mas aqueles que "convenceram seus pares a adotar suas ideias e técnicas" (Geison, 2002, p.23), e que esse convencimento depende das expectativas institucionais e políticas. Analisar a vitória de uma forma específica de caracterizar a "higiene" não pressupõe que essa seja mais verdadeira ou necessariamente mais eficaz que as demais: ela foi a que respondeu melhor a demandas locais. A eleição de uma visão particular de "o que deve ser feito de acordo com a ciência" surge imbuída de prioridades governamentais.

Como se procurará demonstrar, há fundamentos diferentes que unem os teóricos escolhidos. Uma ideia central funciona como fulcro ao termo para determinada vertente de pensamento higienista, mas se distancia de outro pensamento a respeito do que é higiene, a ponto de não haver contato entre as definições. Na Grécia e no Renascimento, higiene era um conjunto de saberes para o cuidado de si. Com a economia política, o termo passou a ser disputado devido à concorrência interna que ora buscava a satisfação dos interesses dos mandantes e se amparava na dedução lógica, e ora se ancorava no pensamento estatístico e religioso.

\section{Do Renascimento à economia política}

De acordo com as fontes pesquisadas, o cuidado com a higiene, por meio de uma atividade racionalmente elaborada, surgiu na Grécia Antiga e reapareceu no Renascimento, na obra de Luigi Cornaro, ${ }^{2}$ como um saber específico sobre o prolongamento da vida. $\mathrm{Na}$ Modernidade, a higiene se tornou um ramo da economia política: personagens que foram importantes homens de Estado teorizaram a respeito de como manter a nova "riqueza das nações", o trabalho, pois era aquilo que determinava o real valor de troca das mercadorias (Smith, 2001, p.18). E se Adam Smith abre o seu livro clássico afirmando que o aperfeiçoamento das forças produtivas é a divisão do trabalho, era necessário estudar esse fenômeno que passava a enriquecer as nações, conhecê-lo por meio da demografia, da análise da expectativa de vida, da observação das variáveis que poderiam otimizar cada elemento (o trabalhador) dessa cadeia etc.

O cuidado de si próprio, ou da própria saúde, como forma de prolongamento da vida tem em Cornaro o grande nome da era moderna ocidental. Teve inúmeros seguidores, por toda Europa e América durante os séculos posteriores, que escreveram a respeito de higiene, como, por exemplo, Christoph Hufeland e Bernardino Ramazzini, na Europa, e Benjamin Franklin, nos EUA. E o conceito de higiene, conforme já se mencionou, variava de conotação de autor para autor: os teóricos tinham a necessidade de observar as possibilidades de ser ou não ouvidos e obter o mecenato das instituições científicas ou do próprio Estado. Logo, quando desenvolviam suas teorias, as escolhas eram também políticas.

Na virada do século XVIII para o XIX, consolidou-se teoricamente a noção de que o Estado não deveria apenas garantir a sua soberania, mas também assegurar a "população" (Foucault, 2008a). A influência de William Petty (1623-1687) sobre o pensamento político 
no que diz respeito à necessidade de o Estado tomar medidas para aumentar o número de súditos não ficou restrita apenas às Ilhas Britânicas, mas foi absorvida por teóricos de Estado da Europa continental. Médico de formação, Petty foi precursor do que se poderia chamar hoje de "ciências sociais", ao sugerir o estudo da população irlandesa e criar a sua "aritmética política", ou seja, basicamente, sugerir que o Estado deveria ter a preocupação de "governar a população" e aumentá-la (McCormick, 2009). Pelo fato de a Europa ter passado pelo fenômeno do despovoamento no século XVIII, surgiram tratados que observariam o conjunto de súditos não apenas no seu aspecto jurídico-político, mas também biológico. Nesse momento, a higiene se tornou assunto político estratégico, e da higiene pessoal passava-se a pensar a respeito da higiene social. É o nascimento do que alguns autores chamariam de "medicina social" (Foucault, 1979), outros de "saúde pública" (Rosen, 1993) ou, ainda, de "medicina de Estado" (Ryan, 1836).

\section{A aristocracia renascentista cuidando da própria saúde: o higienista Luigi Cornaro}

Já que um homem não pode ter melhor médico do que ele próprio e nem ter melhor medicina do que a vida equilibrada, ele deve, de todas as formas, adotar essa vida (Cornaro, 1917, p.58). ${ }^{3}$

Gruman (1966) dedicou-se a analisar, em alargado período histórico, o pensamento sobre a vida e os teóricos que pretendiam estendê-la em seu limite. Partindo da sempre atual premissa de que a questão filosófica central para a humanidade é a morte, o autor se debruçou sobre fontes e argumentos de pensadores, cientistas e literatos para entender como a ideia de "prolongar a vida" foi compreendida em períodos diversos da história da humanidade. Em sua vasta pesquisa, passou pelas escritas do Novo e do Velho Testamentos, pelos tratados dos alquimistas, pela cultura chinesa, grega e outras, produzindo um considerável estudo de história das mentalidades.

Cornaro era um típico membro da aristocracia italiana durante o Renascimento. Nascido em 1467, em Pádua, recuperou a riqueza e o prestígio de sua família, foi patrono das artes e membro de um círculo importante de pensadores. Cornaro, em seu mais conhecido trabalho, Discursos de uma vida equilibrada ou de temperança, relata a sua saúde deteriorada e frágil entre os 35 e os 40 anos de idade, situação causada pelo seu modo de vida sem cuidados e de prazeres e como, após adotar uma série de atitudes de "higiene", não só se recuperou como atingiu os 99 anos de forma saudável e lúcida. Gruman aponta os escritos de Cornaro como relevante contribuição na circulação das ideias sobre o prolongamento da vida, atribuído ao equilíbrio da alimentação e também à renúncia dos excessos.

Walker (1954) apresenta aspectos centrais do pensamento desse autor que influenciou de forma importante o conceito sobre higiene e prolongamento da vida em seu tempo e em períodos posteriores. Walker aponta que, para Cornaro, o essencial era a valorização do corpo e a autonomia possível sobre ele em oposição à ideia vigente do corpo e da alma a serviço do poder religioso. A oposição seria entre o descompasso, excesso, abuso versus autonomia e vontade, e o valor individual da superação. 
O regramento da dieta alimentar, assumido após uma grave deterioração física, era a questão central para Cornaro (1842, p.13), apresentando uma perspectiva moral e física:

Tendo então recuperado a minha saúde, comecei a considerar seriamente o poder da temperança e disse a mim mesmo que, se essa virtude teve eficácia suficiente para abrandar tais graves doenças como as minhas, ela deve ser ainda melhor para preservar-me saudável, para ajudar a minha má constituição e confortar o meu estômago extremamente frágil. Então, eu me dediquei diligentemente a descobrir quais tipos de comida me caíam melhor.

Alimentação pouca, regrada e basicamente de pão, frutas e uma pequena quantidade de vinho era por ele preconizada como higiene pessoal e alimentar que poderia levar ao alcance da moralidade, fundamental para viver mais e melhor. Higiene pessoal, ainda não social, não integrada ao "espaço externo" ou ao "outro".

Embora a higiene denominada por Cornaro no período estivesse relacionada ao "cuidado de si", principalmente no que diz respeito à alimentação e ao cuidado com os excessos, Walker (1954) aponta que o higienista contribuiu em seus últimos anos com algumas benfeitorias públicas ligadas à limpeza e drenagens para aumentar a área de cultivo de alimentos e, por conseguinte, o abastecimento da cidade, além de tornar mais saudável o ar para os habitantes. Assim, a ideia de higiene pessoal como possibilidade de prolongamento da vida para Cornaro saía do espaço individual para o coletivo, pelo menos em algumas ações pontuais.

Entre outras publicações, Cornaro, o higienista renascentista, escreveu aos 83 anos de idade, em 1530, o Tratado de uma vida sóbria. Nessa obra, que seria traduzida e adaptada em outros tratados pela Europa, o autor relata sua dieta e seu método de higiene pessoal para prolongar a vida, além do que aponta serem as três principais vantagens de seu modo de vida: evitar as intemperanças, preservar a saúde e a felicidade, e capacitar o indivíduo para uma velhice saudável e tranquila.

A circulação das ideias de Cornaro foi bastante considerável, tanto na Europa quanto no Novo Mundo. Temos como exemplos de seguidores: Leonard Lessius (1554-1632), jesuíta belga; Bernardino Ramazzini (1633-1714), médico italiano; Richard Lower (1631-1691), médico inglês; sir John Sinclair (1754-1835), político e escritor escocês; Benjamin Franklin (1706-1790) jornalista, político e diplomata estadunidense; Christoph Hufeland (17621836), médico alemão; Sylvester Graham (1794-1851) ministro presbiteriano estadunidense, precursor do vegetarianismo; Piero Maroncelli (1795-1846), patriota, músico e escritor italiano; Joseph Addison (1672-1719), poeta e ensaísta inglês que escreveu ensaios para o The Guardian; William Temple (1881-1944), sacerdote anglicano inglês; William Sweetser (1797-1875), médico inglês que tratou de higiene mental; Daniel Harrison Jacques (18251877) especialista na ciência dos temperamentos.

Para este artigo, faz-se importante deter-nos sobre dois deles: Franklin, com a sua ética individual que visava ao aprimoramento pessoal; e Hufeland, que, apesar de também entender a ética e uma rotina pessoal saudável como atitudes que poderiam levar os homens aos duzentos anos, estava envolvido em um projeto mais amplo (religioso, filosófico, antropológico e político) de nação alemã de acordo com os anseios de uma burguesia ascendente. 


\section{O legado da higiene como cuidado de si: Benjamin Franklin, Christoph Hufeland}

Benjamin Franklin foi um dos Founding fathers dos EUA. Foi jornalista, político, diplomata, escritor. Sua Autobiografia, iniciada em 1771, foi publicada postumamente.

Nota-se em Franklin uma extrema disciplina com relação ao cuidado da própria vida cotidiana: sua família era protestante, e ele teve uma educação presbiteriana (Franklin, 1963, p.6-76). Procurou descobrir quais eram as virtudes mais importantes de um homem e desenvolveu um método para tentar alcançar todas. De início, eram 12 as virtudes enumeradas por Franklin, mas um colega quaker o havia advertido do seu orgulho. Assim sendo, ele resolveu acrescentar a 13a, a humildade. Enfim, as $13^{\text {a }}$ virtudes são:

1 - Temperança

Não comas até o entorpecimento; não bebas até a exaltação.

2 - Silêncio

Não fales senão o que possa beneficiar aos outros ou a ti; evita conversa frívola.

3 - Ordem

Que todas as tuas coisas tenham seus lugares; que cada parte de tua atividade tenha seu tempo.

4 - Resolução

Resolve realizar o que deves; realiza sem faltar com o que resolves.

5 - Frugalidade

Não faças despesa alguma a não ser para o bem de outros ou de ti; isto é, não desperdices coisa alguma.

6 - Diligência

Não percas tempo; emprega-o sempre em algo útil; suprime todas as ações desnecessárias.

7 - Sinceridade

Não uses ardis lesivos; pensa com inocência e justiça, e, se falares, fala do mesmo modo.

8 - Justiça

Não prejudiques ninguém fazendo o mal ou omitindo os benefícios que são do teu dever.

9 - Moderação

Evita os extremos; não te ofendas com injúrias tanto quanto pensas que elas merecem. 10 - Limpeza

Não toleres falta de limpeza no corpo, nas roupas ou na habitação.

11 - Tranquilidade

Não te deixes perturbar por ninharias ou por acidentes comuns ou inevitáveis.

12 - Castidade

Usa raramente dos prazeres carnais, apenas por motivo de saúde ou reprodução, nunca até o entorpecimento, à fraqueza ou em prejuízo da tua própria paz ou reputação de outrem.

13 - Humildade

Imita Jesus e Sócrates (Franklin, 1963, p.78).

Desenvolveu um método para exercitar em uma semana a maneira de adquirir todas as virtudes que considerava importante: tratava-se de marcar as faltas, durante a semana, que havia cometido com relação a todas e tentar não cometer nenhuma vez a escolhida. Franklin (1963) realizava esse exercício (que cunhou de curso) quatro vezes por ano. 
Era também autorregulado nos seus horários: das cinco às sete horas, levantava-se, se lavava, dizia a oração "Poderosa bondade!", organizava as atividades do dia e tomava o café da manhã. Das oito às onze horas, trabalhava; do meio-dia à uma, costumava ler ou examinar as contas e almoçava; das duas às cinco horas, trabalhava; das seis às nove, organizava suas coisas, jantava, escutava música ou tinha algum outro tipo de diversão e fazia o exame de consciência do dia; das dez às quatro da manhã, dormia.

Não surpreende que tenha tido Cornaro em grande estima. A sua primeira virtude, temperança, certamente é uma inspiração do higienista italiano. Contudo, se a primeira apresenta afinidade de conteúdo com Cornaro, toda a relação, com sua organização pessoal, seria uma mescla da religiosidade mundana típica do protestantismo com a experiência de cuidado de si que provinha da higiene.

Christoph Wilhelm Hufeland é um dos nomes mais lembrados pela historiografia médica quando são mencionados os seguidores de Cornaro. Como estudioso da fisiologia, poderia fornecer a dimensão antropológica do projeto romântico burguês alemão que se opunha à aristocracia germânica ligada às cortes francesas.

Elias (1994) historicizou a diferença alemã entre Kultur (cultura) e Zivilisation (civilização) como sendo, de um lado, a virtude autêntica do cultivo de si e, de outro, a cortesia externa e enganadora da atitude cortesã considerada civilizada. Johann von Goethe (1746-1832) teria sido um dos mais importantes intérpretes dessa corrente germânica de pensamento. Tratava-se da ascensão da burguesia alemã, em busca da legitimidade histórica que lhe era negada e oferecida ao poder cortesão da aristocracia. Havia um projeto, próprio, identitário por parte da classe alemã emergente que visava a um destino específico aos que cultivassem a Bildung (educação), a Kultur e a Aufklärung (esclarecimento) (Solon, 2014, p.3) como uma versão a oeste do Reno do Iluminismo.

Hufeland estava próximo à ideia de que a patologia seria fruto da liberdade humana em direção ao pecado. A realização física do homem, portanto, seria o cultivo da moralidade e, assim, estava se configurando uma medicina moralizante em versão alemã ou, em outras palavras, uma "fisiologia ética", tendo uma clara inspiração em Immanuel Kant (1724-1804), com quem Hufeland manteve correspondência a respeito da velhice, da vida prolongada e do seu significado moral (Foucault, 2011, p.38-39).

A literatura ofereceria os ideais humanistas, a filosofia traria a razão como possibilidade de passagem do homem para a maioridade, assim como a fisiologia de Hufeland seria o conhecimento antropológico necessário para estender a vida humana a duzentos anos, graças ao conhecimento adquirido da natureza e do indivíduo para auxiliar o processo natural de cura (Solon, 2014, p.10), cura da imoralidade e, consequentemente, da doença.

Hufeland seria, portanto, um intérprete da medicina que colocou o cuidado de si humanista de Cornaro sob um diapasão abertamente ético, religioso e racional e, por isso, trouxe o cuidado de si individual para o projeto de Herrenvolk, "senhores da nação" que detêm o domínio do destino, da coletividade e de si próprios. E, por isso mesmo, como classe, teriam o direito à supremacia.

Tanto Franklin quanto Hufeland seriam, portanto, uma sequência do cuidado de si de Cornaro transformado em "social", pois visava ao melhoramento do grupo identitário, 
fosse pelo exemplo ou pelo conselho. O viés religioso fica claro, nesses casos, mas ainda não havia estatística.

\section{O ouro não é a riqueza das nações}

Maquiavel (1469-1527) é estudado como o pai da ciência política moderna. Polemizando com essa concepção, Foucault (2008a, p.85) afirmou que "longe de pensar que Maquiavel abre o caminho para a modernidade do pensamento político, direi que ele assinala, ao contrário, o fim de uma era". O pensador florentino, preocupado com a unificação italiana, teorizou a respeito da soberania e da razão de Estado, assim como apresentou uma série de medidas militares e administrativas para assegurar a integridade territorial. Uma vez que a riqueza de um reino era o ouro, a tarefa do rei era garantir seu território e o seu erário. Contudo, a importância do cultivo da terra, para não dizimar a população europeia pela fome, e a Guerra dos Trinta Anos (1618-1648), que devastou as populações da região e só terminou com a Paz de Vestfália, foram circunstâncias que motivaram reflexões sobre outra responsabilidade do Estado: a de governar. A necessidade de governar surgia relacionada à percepção de que mais relevante do que o entesouramento passaria a ser o trabalho. A arte de governar passaria a ter outro saber orientador: a ciência econômica.

A preocupação com a atividade econômica previa outros tipos de estudos e atividades por parte do rei. Não mais tratados a respeito de meios e fins para manter e/ou conquistar domínios, mas verificar e, caso possível, impulsionar a atividade produtiva. Os tratados jurídicos a respeito do direito ao comando e a arte militar continuariam tendo importância para o Estado, mas o quadro dos saberes foi complementado pela estatística; afinal, um novo objeto de estudo entrava em cena: a população.

é graças à percepção dos problemas específicos da população e graças ao isolamento desse nível de realidade que se chama economia, que o problema do governo pôde enfim ser pensado, refletido e calculado fora do marco jurídico da soberania. E essa mesma estatística que, nos marcos do mercantilismo, nunca tinha podido funcionar, senão no interior e, de certo modo, em benefício de uma administração monárquica que funcionava, por sua vez, na forma da soberania, essa mesma estatística ... [se tornou] o fator técnico principal, ou um dos fatores técnicos principais, desse desbloqueio (Foucault, 2008a, p.138).

A partir desse momento, a economia política tinha como eixo principal o estudo da potencialidade produtiva do conjunto de homens que faziam parte do Estado: potencialidade que poderia ser mensurada pelo número de súditos, pela saúde deles e pelos índices de morbidade e mortalidade. Portanto, para o splendeur de l'Etat (esplendor do Estado), como diriam os franceses, ou para a oberste Gewalt (poder supremo), como defendiam os alemães, o soberano precisaria passar a observar o bem-estar dos concidadãos e promover a "felicidade social". Esse novo conjunto de saberes, preocupações e intervenções, Foucault chamou de "governamentalização", ou seja, a gestão da população, como espécie biológica, por parte do Estado. Em outras palavras, foi quando os agentes e teóricos de Estado desenvolveram a biopolítica e assumiram a "higiene" como conhecimento a ser gerido socialmente: ou seja, passaram a entender como fundamental a elaboração de uma "higiene social". 
Tanto Rosen (1993) quanto Foucault (2008a) apontam meados do século XVIII como o momento em que tais preocupações e intervenções do Estado com relação à saúde pública se iniciam. O marco pode ser um pouco mais estendido;, afinal, os primeiros a chamarem a atenção sobre o estudo de terras, populações e produção são teóricos do século XVII. William Petty (1623-1687), na Inglaterra, Nicolas De La Mare (1639-1723), na França e, no século seguinte, Johann Heinrich Gottlob von Justi (1720?-1771), no território germânico escreveram sobre a novidade de governar a população. E o saber do governo dos homens era, naquele momento, chamado de polícia: “Apenas no século XVIII difunde-se entre os próprios agentes históricos envolvidos com tarefas de Estado a noção de polícia (as nossas modernas 'políticas públicas')" (Pereira, 2001, p.382; destaque nosso). Portanto, a estatística era o conhecimento necessário ao Estado para exercer a polícia, ou seja, governar de forma sábia e prudente para melhorar, prolongar e tornar mais produtiva a vida dos seus súditos.

William Petty era médico. Foi o primeiro a desenvolver um sistema de coleta de dados estatísticos baseado na divisão do trabalho dos pesquisadores. Por isso, o trabalho do qual foi incumbido, que muitos supunham que duraria décadas, durou meses: tratava-se de fazer a classificação das terras irlandesas. Foi o primeiro a fazer uma análise quantitativa empírica que levantasse os recursos naturais e sociais para a promoção da agricultura e mercado. Não à toa, Karl Marx o considerava o "fundador da economia política". Petty acreditava que a Inglaterra poderia obter bons resultados econômicos e políticos se controlasse a demografia, mas, para controlá-la, era necessário conhecê-la (McCormick, 2009, p.1-13).

Petty interessava-se pela mecânica da sociedade, pois supunha a existência de leis sociais, assim como conhecia as leis naturais. Uma ciência empírica, observável, testável e manipulável era possível não apenas nos laboratórios, mas também na sociedade. E foi com essa certeza que pôde colocar em prática a sua aritmética política como uma "medicina política da Irlanda" (McCormick, 2009, p.8). Petty tornou-se o homem de ciências responsável pela estatística das terras brutalmente invadidas por Oliver Cromwell (15991658): era o tecnocrata responsável pelas aferições dos terrenos produtivos a desapropriar de irlandeses católicos para distribuir aos soldados ingleses. Civilizar os irlandeses passou a ser uma preocupação de primeira ordem tanto de Cromwell quanto do Hartlib Circle, um grupo de correspondência de intelectuais de toda a Europa Central com base em Londres, onde vivia Samuel Hartlib (1600-1662). "Civilizar" significava basicamente colonizar as terras e transformar os irlandeses em ingleses ou trabalhadores de posses inglesas, pois o trabalho irlandês era necessário para a prosperidade inglesa. As medições de Petty, denominadas Down Survey, eram "o instrumento científico de um governo militar [que] 'transformou' a sociedade" (McCormick, 2009, p.102; destaque no original).

A expropriação de terras contava com o apoio de alguns protestantes irlandeses, como Vincent Gookin (1616?-1659), que escreveu um panfleto sugerindo a transplantação dos irlandeses nativos para Connaught, uma província a oeste da ilha, ideia da qual Petty não partilhava. Em vez de sugerir a transplantação, ele propunha a transmutação; transmutação de irlandeses em ingleses. Por isso, Petty passou a analisar o comportamento diferenciado dos "confederados" e dos "separatistas", o efeito que as religiões tinham nos hábitos, relacionando-os com a "astrologia judicial", uma ciência amplamente aceita à época. 
Tendo ajudado John Graunt (1620-1674) nos seus estudos a respeito da mortalidade, Petty viu a população transformada em "número, peso e medida" (McCormick, 2009, p.119), e, logo, o conhecimento necessário para a arte de governar estava completo. Desenvolvia-se, assim, uma ciência social.

Para governar, segundo Petty, era necessário tomar medidas legais, estabelecer divisões distritais e eclesiásticas, racionalizar o sistema de impostos para que a agricultura e a manufatura fossem as mais rentáveis possíveis; promover a saúde dos súditos analisando o ar, as terras, as estações, assim como fornecer o número de médicos necessários em cada região; criar um sistema tributário "natural", ou seja, que otimizasse o mercado, visto como atividade "natural" dos homens; ensinar algum ofício aos mendigos "vagabundos" porém saudáveis, assim como aos doentes depois de curados. Não coincidentemente, os primeiros registros de workhouses ${ }^{4}$ inglesas são desse período.

John Bellers (1654-1725), que também enfatizava a necessidade de fazer os preguiçosos trabalharem e de que se promovessem meios de evitar doenças, sugeriu, em 1714, a criação de um instituto nacional de saúde, de hospitais e laboratórios para ensino médico, assim como assistência para os pobres enfermos (Rosen, 1963, p.21-22). Para Bellers, a Grã-Bretanha perdia aproximadamente cem milhões de possíveis trabalhadores devido a doenças que poderiam ser curadas (Risse, 1992, p.176).

Nicolas De La Mare (ou Delamare, como o escrevia Foucault), nos seus extensos escritos do Traité de police de início dos Setecentos, afirmava que o objetivo da polícia era "levar o homem à mais perfeita felicidade de que ele possa desfrutar nesta vida" (De La Mare citado em Foucault, 2008a, p.439). A felicidade e o bem-estar dos súditos resultariam em força e esplendor estatal, e, por isso, as práticas da polícia teriam mais similaridade com os poderes do príncipe do que com os do juiz:

o direito de Polícia consiste propriamente em poder fazer regulamentos particulares para todos os Cidadãos do seu distrito e território. O que excede o poder de um simples juiz que não tem outro poder senão o de pronunciar entre demandante e defensor ... Assim, esse poder se aproxima e participa muito mais do poder do Príncipe do que do Juiz, dado que esses regulamentos são como leis e ordenanças particulares, que também são chamadas propriamente de Éditos (De La Mare citado em Foucault, 2008a, p.485).

De La Mare enumerou 11 domínios que seriam de competência da polícia: (1) religião; (2) disciplina dos costumes; (3) saúde; (4) víveres; (5) segurança e tranquilidade pública; (6) estradas; (7) ciências e artes liberais; (8) comércio, manufatura e as artes mecânicas; (9) servidores domésticos; (10) operários; e (11) pobres (Foucault, 2008a, p.483). ${ }^{5}$ Como se nota, as competências da polícia são diversas e ocupam quase a totalidade da vida dos súditos, lidando com os detalhes da vida cotidiana que se somavam a políticas macro de governo. Ao mesmo tempo que se buscava certa pedagogia dos costumes, também se atentava à promoção da saúde, à qualidade dos víveres consumidos; e se tratava da fluidez da circulação de commodities e manufaturas; da atenção aos trabalhadores e assistência aos pobres. Além da razão de Estado, o príncipe passava a ocupar-se com uma nova razão governamental, que administraria a produtividade do solo, a agricultura e a pecuária (para impedir a escassez alimentar), assim como a circulação de pessoas, segurança e tranquilidade 
nas cidades. O cuidado com a minúcia dos indivíduos e a regulação das grandes atividades sociais do reino tinha o objetivo de produzir o que esses autores chamavam de bem-estar, o que, ao mesmo tempo que produzia "felicidade social", proporcionava a possibilidade de crescimento das forças do Estado.

Nos Estados germânicos, Melchior von Osse (1506?-1557) e Georg Obrecht (1547-1612) são considerados importantes precursores do que se soeu chamar de "cameralismo", seguidos por Joseph von Sonnenfels (1733-1817). Osse e Obrecht relacionaram saúde pública e pobreza e pensaram sistemas tributários, e Obrecht afirmava que era do interesse estatal que os súditos recebessem o máximo de salário possível, assim como deveria haver seguros e poupanças (Backhaus, 2010, p.172). Nessa tradição, o nome mais importante da ciência de governo do século XVIII nos países germânicos é Gottlob von Justi.

Curiosamente, os pensamentos provindos dos Estados germânicos costumam ser denominados diferentemente. A economia política dos alemães tem um nome próprio, o "cameralismo"; da mesma forma, o pensamento germânico que se consolidou na passagem do século XVIII para o XIX a respeito da saúde pública é chamado de "polícia médica", o que seria considerado muito diferente do que foi produzido em outras partes do continente (Rosen, 1963, 1979, 1993; La Berge, 1992). Observando-se as fontes, entretanto, nota-se que as diferenças nos diagnósticos e prognósticos não eram tão antagônicas quanto sugeriu a historiografia a respeito: a oeste do Reno, os sanitaristas não apresentaram menosprezo pelo conceito de polícia médica; ao contrário, foi amplamente debatido (Mantovani, 2017). Da mesma forma, não se poderia afirmar que a economia política produzida pelos germânicos do século XVIII foi substancialmente diferente da produzida no restante do continente. Risse (1992, p.172), ao falar sobre economia e saúde pública alemãs, refere-se ao "mercantilismo alemão - o então chamado cameralismo". O termo cameralismo advém de Cameralwissenschaft, ou seja, "ciência cameral"; afinal, os conselhos tradicionais dos príncipes germânicos foram substituídos pelas "câmaras", de onde se originavam as recomendações e propostas administrativas ao príncipe (Stolleis citado em Foucault, 2008a, p.34). O fato de que se chamavam "câmaras" os postos dos conselheiros não nos parece motivo suficiente para que um saber seja considerado demasiado particular.

Gottlob von Justi, considerado o grande nome do cameralismo, pode ser também entendido como um teórico da economia política cujas ênfases e subestimações nos seus textos não diferem substancialmente dos economistas de outras regiões europeias da época. Justi esteve preocupado com o bom governo e a boa polícia, ou seja, metodizar as medidas a ser tomadas pelo Estado para a felicidade social com a finalidade de obter o máximo de poder político (Schmidt, 2010, p.158) ou o reipublicae splendorem, "esplendor da república", conforme dizia Peter Carl von Hohenthal (1754-1839) (Foucault, 2008a, p.439). A felicidade social, para Justi, deve ser buscada com educação e saúde: é necessário prolongar a vida e aumentar a população, assim como educá-la.

A necessidade de aumento da população ganhou uma importância proeminente nos escritos de Justi: o cuidado com a infância era um tema crucial, e a facilitação da fecundidade era outro ponto recorrente. Posteriormente, a crítica ao celibato foi uma questão importante de quase todos os tratados de polícia médica da Europa (Mantovani, 2017). 
Nos Estados germânicos, o aumento do número de súditos também poderia ser feito por meio da promoção da imigração.

Em suma, tal política tinha como princípios:

- melhoria do conhecimento disponível;

- melhoria da saúde da população;

- fortalecimento das normas sociais;

- educação infantil;

- em particular, às crianças deve ser ensinado um trabalho, a fim de as preparar para

posteriormente participar no processo de produção;

- pessoas incapacitadas devem participar do processo de produção

- aumento da natalidade;

- atração de novos habitantes para o país;

- incentivos para que os habitantes do país aí permaneçam;

- penas humanas para atos criminosos;

- prevenção de guerras;

- em caso de guerra, minimização dos seus efeitos negativos (Backhaus, 2010, p.174).

Justi via a necessidade de racionalização da tributação para adequar a produtividade às demandas do país. Seguindo o exemplo da Inglaterra, Justi defendia que as corporações de ofício e a sociedade civil decidissem a quantidade anual a ser paga ao Estado (Schmidt, 2010, p.161).

Também da Inglaterra vinha o exemplo com relação ao tratamento dos vadios: sugeria a criação de workhouses ostensivas para que aqueles que ainda insistissem em mendigar fossem forçados a nelas trabalhar. Contudo, Justi advertia que "não é necessário manter as pessoas à base de água e pão e maltratá-las com surras diárias, exceto aquelas que não seguirem a rotina de trabalho cotidiana" (Backhaus, 2010, p.179). Tratava-se do fortalecimento das normas sociais e, nesse caso, da inculcação da importância do trabalho.

Um traço que correlaciona fortemente todos esses autores é a preocupação com a subalimentação. Impedir a fome era um dos pilares para se aumentar e prolongar a vida da população. À exceção dos irlandeses, impedir a morte por inanição era sabidamente a questão fisiológica básica a ser alcançada pelo governo para se buscar a "felicidade social".

Pode-se concluir que os séculos XVII e XVIII foram aqueles em que as práticas de cuidado individual foram apropriadas como práticas de governo. Como já dito, Cornaro foi uma espécie de compilador do conhecimento sobre o cuidado que uma pessoa pode ter sobre o próprio corpo. Franklin e Hufeland estabeleceram as bases morais e religiosas para que esse cuidado se tornasse uma prática a ser assumida por um agrupamento identitário. Por outro lado e concomitantemente, havia os estudiosos que começaram a se dedicar à estatística, estabelecendo esse saber como um importante ramo do conhecimento de Estado. Da união entre a estatística e a higiene de até então, surge a higiene pública, uma das ferramentas mais importantes para o governo eficaz da economia política.

Lemke (2012, p.3) afirma que o conceito de governamentalidade, criado por Foucault, media poder e subjetividade, o que "torna possível investigar como processos de dominação estão relacionadas a 'técnicas de si' ... e como formas de governo político estão articuladas com práticas de autogoverno" (destaque no original). Foucault (2008a, p.3) pretendeu 
estudar a maneira "como a sociedade, as sociedades ocidentais modernas, a partir do século XVIII, voltaram a levar em conta o fato biológico fundamental de que o ser humano constitui uma espécie humana", ou seja, a biopolítica. O cuidado de si se transformava em cuidado de todos, com fins políticos:

A análise foucaultiana da governamentalidade examinou como ligações de (a) a saúde da população com (b) a economia e a segurança política do Estado resultaram em distintas estratégias 'biopolíticas' por representar e agir sobre a população durante governamentalidades liberais (Nadesan, 2008, p.93; destaque no original).

Foi levando em conta o aspecto biológico da população que o Estado passou a se ocupar com o governo, portanto, o que foi acionado como demanda da economia política constituiu uma governamentalização biopolítica das estratégias do Estado.

\section{Preservar a riqueza da nação cientificamente: a estatística e a higiene pública}

Estatística e polícia se tornaram aspectos fundamentais de governo. De um lado, temos Auget de Montyon (1733-1820), e, de outro, Johann Peter Frank (1749-1821). Interessa-nos a obra que ficou com o nome de seu secretário, Moheau, mas cuja responsabilidade era dele, Montyon: Recherches et considérations sur la population de la France, de 1778. No século em que houve despovoamento pela Europa sem ter sido efeito de nenhuma epidemia excepcionalmente grave, fazia-se necessário tentar entender o fenômeno. Para tanto, realizou-se uma investigação apurada em todo o país. Peter Frank, médico e higienista natural de Rodalben, utilizou-se das estatísticas europeias a que teve acesso para escrever o seu System einer vollständigen medicinischen Polizei, que foi traduzido mundialmente como Sistema completo de polícia médica. Contudo, essa obra deve ser entendida como "Sistema completo de administração pública da saúde", devido ao fato de o termo polícia se referir à administração pública por parte do Estado, conforme já apontado acima.

Tanto Montyon quanto Frank foram influências continentais em boa parte da Europa a respeito da necessidade de estudar a população e intervir para aumentar o número de cidadãos e seus anos de vida. A França pode ser considerada pioneira, tendo sido o palco do primeiro Movimento de Saúde Pública (La Berge, 1992). O grupo, cujos nomes principais são Louis-René Villermé (1782-1863) e Alexandre Parent du-Châtelet (17901836), criou, em 1829, o periódico cunhado Annales d'Hygiène Publique et de Médecine Légale, considerado um marco na história da saúde pública ocidental (Ackerknecht, 1948; Coleman, 1982; La Berge, 1992). O periódico foi a consolidação das principais reflexões do grupo.

Utilizando-se das tabelas estatísticas que tinham à disposição, fizeram cruzamentos de dados para compreender as causas de morbidade e mortalidade de Paris. Observaram os arrondissements parisienses mais secos, mais pantanosos, mais próximos de açougues, com muitos ventos, com poucos ventos, mais ricos, mais pobres e chegaram a uma conclusão: a única correlação que se pode fazer com doença e mortalidade é a pobreza, conforme concluía Villermé na quase totalidade de suas memórias publicadas nos Annales. Ao se posicionarem dessa forma, colocaram em xeque a teoria milenar dos miasmas que era, à 
época, o grande problema com o qual os administradores urbanos lidavam. Se os miasmas existissem - afirmava o grupo -, eles não eram cientificamente relevantes (La Berge, 1992).

Dessa forma, sendo a causa principal de doença e morte o sistema econômico, tratavase de uma teoria politicamente difícil de ser aceita, devido à necessidade de mudanças estruturais na sociedade. Portanto, apesar do aparente conflito entre racionalidade e religião, Frank e os primeiros sanitaristas franceses foram os que utilizaram métodos considerados os mais científicos (os números trazidos pelas tabelas estatísticas) para afirmar uma máxima cristã: a necessidade de menos desigualdade econômica. Os principais nomes do movimento higienista francês eram "pios cristãos" (Ackerknecht, 1948, p.145). Com base nos dados empíricos, a máxima foi dada em finais do século XVIII pelo pai da polícia médica:

Deixe os legisladores, se eles puderem, manter afastadas das fronteiras o mortífero contágio de doenças ameaçadoras! Deixe-os alocar, por todas as províncias, homens distintos na ciência da medicina e da cirurgia! Deixe-os aprovar regulamentos de inspeção de farmácias e deixe-os aplicar muitas outras medidas para a saúde dos cidadãos. Mas deixe-os negligenciar uma única coisa, isto é, a necessidade de eliminar ou tornar mais tolerável a mais rica fonte de doenças, 'a extrema miséria do povo', e os senhores dificilmente verão qualquer benefício da legislação de saúde pública (Frank, 1941, p.90; destaque no original).

\section{Uma outra higiene pública: a racionalidade que impõe a limpeza}

O médico e higienista Alexandre Parent du-Châtelet publicou Les chantiers d'équarrissage de la ville de Paris envisagés sous le rapport de l'hygiène publique (Os edifícios do matadouro de cavalos da cidade de Paris contemplados no relatório de higiene pública), estudo que não encontrou mais vítimas de cólera entre os que moravam próximo ou trabalhavam em Montfoucon (o açougue de cavalo) do que em outras localidades; portanto, as emanações pútridas de sangue, ratos, água estagnada, fedores horríveis não causariam necessariamente mal à saúde (La Berge, 1992, p.219-227). Se o matadouro fosse retirado dali, seria por uma razão estética; assim como seria unicamente por estética a retirada da manufatura de tabaco da cidade (Coleman, 1982, p.296). Entretanto, a Comissão de Salubridade - embora desse ouvidos a Parent du-Châtelet pelo prestígio científico que possuía - tinha que responder a uma demanda social pela eliminação das tais emanações pútridas, os miasmas e os odores que, pensava-se milenarmente, causavam doenças. Por isso, ela expressou a sua opinião a respeito do matadouro nos seguintes termos: "Já para nós, ao contrário do raciocínio dos homens da arte e de toda a lógica da ciência, nosso espírito se recusa a crer que estabelecimentos tão infectados como aqueles de Montfaucon não sejam causa de insalubridade" (La Berge, 1992, p.221-223).

Primeiramente, Edwin Chadwick (1800-1890) dialogou e aceitou a "teoria social da epidemiologia" - como ficou conhecida posteriormente - do Movimento de Saúde Pública francês (La Berge, 1988). Contudo, perspicazmente notou a impossibilidade de defender aqueles pontos de vista por inviabilizar qualquer posição dentro do Estado: muito menos problemática era a teoria miasmática, que não tocava na formação socioeconômica da sociedade, e, para que suas profilaxias fossem implementadas, era necessário basicamente 
realizar mudanças técnicas urbanas. Tratava-se de uma teoria inócua politicamente (Hamlin, 1998, p.15). Tratava-se, portanto, da higiene pública com um fundamento diverso daquela de Cornaro, Hufeland, Villermé e du-Châtelet, que, amparada no pensamento racional, concluía que o grande problema era a sujeira, e a solução seria eminentemente técnica, de engenharia urbana. Logo, estava de acordo com os interesses do Estado.

Chadwick escreveu o relatório que viria a público em 1842 intitulado Report to Her Majesty's principal secretary of State for the home department, from the Poor Law Commissioners, on an inquiry into the sanitary condition of the labouring population of Great Britain; with appendices. Tratava-se de um grande apanhado a respeito das condições degradantes dos operários ingleses em que a sugestão era, basicamente, a sugestão de acabar com os miasmas, ou seja, limpeza de casas, ruas, dessecação de pântanos, provisão de água limpa e um sistema de esgoto. E tratava-se de uma forma de imprimir certa disciplina no caráter dos trabalhadores por meio das regulações higiênicas provindas da Comissão da Lei dos Pobres.

O olhar sobre a classe operária, portanto, teve início na França e questionou os efeitos perversos da industrialização sobre o homem, tendo-os como questão principal de adoecimento e morte. A princípio Chadwick, considerado por muito tempo pai da saúde pública, concordou com essa visão, contudo, colocou a Inglaterra na dianteira das reformas sanitárias europeias a partir de 1848 por ter feito um estudo sobre a classe operária para reforçar a necessidade de combate aos miasmas e conseguiu pôr em prática, assim, a "medicina urbana" pela primeira vez na Era Moderna. ${ }^{6}$ Depois viriam outras que seguiriam o mesmo modelo, como a reforma de Paris executada por Georges-Eugène Haussmann (1809-1891) entre as décadas de 1850 e 1860, que impediriam a proliferação de miasmas, assim como levantes populares como os de 1848.

\section{Considerações finais}

Constata-se, a partir da investigação histórica, que o que se defendeu como práticas de higiene e de higiene pública variou sobremaneira de acordo com o pensamento da época e os anseios políticos locais. Variações que iam desde a compreensão de higiene como dieta cuidadosa e temperança (Cornaro, Franklin, Hufeland), necessidade de aliviar os efeitos da pobreza (Frank, Villermé, du-Châtelet) e até limpeza (Chadwick). De um método individual para organizar a vida cotidiana e promover o prolongamento da vida, passou a servir como conceito para a ação do Estado para governar o corpo social como entidade biológica. O conceito ganhou legitimidade científica na passagem do século XVIII para o XIX, tendo uma grande circulação entre os Estados europeus, e capilarizou um ideal de comportamento "higiênico" que foi legitimado pelos diversos tratados de higiene pública.

Pretendeu-se demonstrar as suas mais importantes interpretações e adaptações, por um lado, e os silenciamentos, por outro. Por exemplo, apesar da importante contribuição de Villermé e Parent du-Châtelet, no início do século XIX, Chadwick foi consagrado como o "pai da saúde pública", dado que não é irrelevante: os estudos de Chadwick a partir de 1842 não pressupunham um rearranjo socioeconômico, portanto, eram politicamente inofensivos à ordem inglesa; assim como a teoria de John Snow (1813-1858) de que a cólera 
era transmitida pela água contaminada, a qual similarmente lhe conferiu o título de "pai da epidemiologia moderna".

Conforme afirmado na introdução deste artigo, os grandes cientistas foram aqueles que conseguiram convencer os seus pares das suas ideias e técnicas e, em grande medida, respondiam a uma demanda social particular. A sugestão científica sobre o que deve ser feito está imbuída de prioridades governamentais. Como exemplo atual, temos a escolha do embelezamento urbano em São Paulo, cujo resultado é a desassistência de todo um grupo populacional. Poderíamos, inclusive, supor que a supressão desse grupo é parte do projeto de embelezamento que, sim, pode ser entendido como higiene pública, mas que é incompatível com diversas outras maneiras de compreender a expressão. Essa administração pública, somada à desigualdade social crônica do Brasil, faz dessa sua desassistência uma política de limpeza social.

Contraditoriamente, por outro lado, a ideia renascentista de higiene como uma espécie de cuidado de si retorna atualmente, mas não com o nome de higiene. Atualmente, trata-se de uma responsabilidade individual em que cada um responde pelas suas decisões; afinal, em um contexto em que cada um é empreendedor de si (Foucault, 2008b), o fracasso passa a ser insinuado como um defeito moral pessoal.

\section{AGRADECIMENTO}

O presente trabalho foi realizado com apoio da Coordenação de Aperfeiçoamento de Pessoal de Nível Superior (Capes), por meio de bolsa de pós-doutorado recebida pelo autor Rafael Mantovani, processo n.18.5.231.6.8 - código de financiamento 001.

\section{NOTAS}

${ }^{1}$ Vejam-se, por exemplo, as ações sobre "cracolândias" nos centros urbanos e internações compulsórias de indivíduos que "maculam" a ordem social.

${ }^{2}$ Gruman $(1961,1966)$ e Solon (2014) afirmam que Cornaro teria se inspirado nas ideias orientais. Gruman (1966, p.28-29) argumenta que as ideias sobre longevidade na Europa eram fragmentárias até Cornaro; enquanto, na China, o tema ganhava tratados inteiros e era do interesse de homens de Estado e sábios.

${ }^{3}$ Nessa e nas demais citações de textos em outros idiomas, a tradução é livre

${ }^{4}$ Locais de trabalho e descanso de pobres e para onde eram recolhidos os considerados vadios.

${ }^{5}$ Segundo o editor, Foucault (2008a, p.450) se confunde ao mencionar que seriam 13 domínios e recorre aos originais de De La Mare para apontar que se tratava, na realidade, de 11.

${ }^{6}$ Dessa forma, pode-se afirmar que as visões de Rosen (1993) e Foucault (1979) não encontrariam respaldo empírico nas suas interpretações a respeito das diferenças de saber médico e de medicina social do período.

\section{REFERÊNCIAS}

ACKERKNECHT, Erwin.

Hygiene in France, 1815-1848. Bulletin of the

History of Medicine, v.22, n.1, p.117-155. 1948.

BACKHAUS, Ursula.

Johann Heinrich Gottlob von Justi (1717-1771): health as part of a State's capital endowment. In: Backhaus, Jürgen (Org.). The beginnings of political economy: Johann Heinrich Gottlob von Justi. New York: Springer. p.171-195. 2010.
BOURDIEU, Pierre.

O poder simbólico. Rio de Janeiro: Bertrand Brasil. 2007.

CHADWICK, Edwin.

Report to Her Majesty's principal secretary of State for the home department, from the Poor Law Commissioners, on an inquiry into the sanitary condition of the labouring population of Great 
Britain; with appendices. London: W. Clowes and Sons. 1842.

COLEMAN, William.

Death is a social disease: public health and political economy in early industrial France. Madison: University of Wisconsin Press. 1982.

CORNARO, Luigi.

The art of living long. Milwaukee: William F. Butler. 1917.

CORNARO, Luigi.

The discourses and letters of Louis Cornaro, on a sober and temperate life; with a biography of the author, by Piero Maroncelli and notes and an appendix by John Burdell. New York: Fowler and Wells. 1842.

ELIAS, Norbert.

O processo civilizador. Rio de Janeiro: Jorge Zahar. 1994.

FOUCAULT, Michel.

Gênese e estrutura da antropologia de Kant. São Paulo: Loyola. 2011.

FOUCAULT, Michel.

Segurança, território, população: curso dado no Collège de France, 1977-1978. São Paulo: Martins Fontes. 2008a.

FOUCAULT, Michel.

Nascimento da biopolítica: curso dado no Collège de France, 1978-1979. São Paulo: Martins Fontes. 2008b.

FOUCAULT, Michel.

Microfísica do poder. Rio de Janeiro: Graal. 1979.

FRANK, Johann Peter.

The people's misery: mother of diseases. An address delivered in 1790 by Johann Peter Frank; translated from the Latin, with an Introduction by Henry E. Sigerist. Bulletin of the History of Medicine, v.9, n.1, p.80-100. 1941.

FRANKLIN, Benjamin.

Autobiografia. São Paulo: Ibrasa. 1963.

GEISON, Gerald.

A ciência particular de Louis Pasteur. Rio de Janeiro: Editora Fiocruz. 2002.

GRUMAN, Gerald.

A history of ideas about the prolongation of life: the evolution of prolongevity hypotheses to 1800. Transactions of the American Philosophical Society, v.56, p.9. 1966.

GRUMAN, Gerald.

The rise and fall of prolongevity hygiene, 15581873. Bulletin of the History of Medicine, v.35, n.1, p.221-229. 1961.
GUIMARÃES, Reinaldo.

O mal-estar na saúde pública. Saúde em Debate, v.37, n.96, p.159-188. 2013.

HAMLIN, Christopher.

Public health and social justice in the age of Chadwick: Britain, 1800-1854. New York: Cambridge University Press. 1998.

LA BERGE, Ann.

Mission and method: the early nineteenthcentury French public health movement. New York: Cambridge University Press. 1992.

LA BERGE, Ann.

Edwin Chadwick and the French connection. Bulletin of the History of Medicine, v.62, n.1, p.2341. 1988

LEMKE, Thomas.

Foucault, governmentality and critique. Boulder: Paradigm. 2012.

MANTOVANI, Rafael.

Modernizar a ordem em nome da saúde: a São

Paulo de militares, pobres e escravos, 1805-1840.

Rio de Janeiro: Editora Fiocruz. 2017.

MCCORMICK, Ted.

William Petty and the ambitions of political arithmetic. New York: Oxford University Press. 2009.

NADESAN, Majia.

Governmentality, biopower and everyday life. New York: Routledge. 2008.

PEREIRA, Magnus Roberto.

Almuthasib: considerações sobre o direito de almotaçaria nas cidades de Portugal e suas colônias. Revista Brasileira de História, v.21, n.42, p.365-395. 2001.

RISSE, Guenter.

Medicine in the age of Enlightenment. In: Wear, Andrew (Org.). Medicine in society: historical essays. Cambridge: Cambridge University Press. p.149-195. 1992.

ROSEN, George.

A history of public health. Baltimore: The Johns Hopkins University Press. 1993.

ROSEN, George.

Da polícia médica à medicina social: ensaios sobre a história da assistência médica. Rio de Janeiro: Graal. 1979.

ROSEN, George.

The evolution of social medicine. In: Freeman, Howard; Levine, Sol; Reeder, Leo (Org.).

Handbook of medical sociology. Englewood Cliffs: Prentice-Hall. p.17-61. 1963. 
RYAN, Michael.

A manual of medical jurisprudence and state medicine, compiled from the latest legal and medical works, of Beck, Paris, Christison, Fodere, Orfila, etc. London: Sherwood, Gilbert, and Piper. 1836.

SCHMIDT, Karl.

Justi's concept of taxation. In: Backhaus, Jürgen (Org.). The beginnings of political economy: Johann Heinrich Gottlob von Justi. New York: Springer. p.157-170. 2010.

SMITH, Adam.

Uma investigação sobre a natureza e causas da riqueza das nações. São Paulo: Hemus. 2001.
SOLON, Luiz.

A arte de prolongar a vida, de Christoph Friedrich Wilhelm Hufeland (1762-1836). In: Seminário Nacional de História da Ciência e Tecnologia, 14., 2014, Belo Horizonte. Anais... Belo Horizonte: UFMG. p.1-16. 2014.

VIGARELLO, Georges.

Concepts of cleanliness: changing attitudes in France since the Middle Ages. New York: Cambridge University Press. 1988.

WALKER, William.

Luigi Cornaro, a renaissance writer on personal hygiene. Bulletin of the History of Medicine, v.28, n.1, p.525-534. 1954.

\section{$\rightarrow \rightarrow \rightarrow<<$}

